\title{
Menu labelling is effective in reducing energy ordered and consumed: a systematic review and meta-analysis of recent studies
}

\author{
Jodie Anne Littlewood, Sofia Lourenço*, Cecilie Lauberg Iversen and Gitte Laub Hansen \\ Danish Cancer Society, Strandboulevarden 49, DK-2100 Copenhagen, Denmark
}

Submitted 14 May 2015: Final revision received 10 October 2015: Accepted 9 November 2015: First published online 30 December 2015

\begin{abstract}
Objective: Menu labelling is a practical tool to inform consumers of the energy content of menu items and help consumers make informed decisions in the eatingout environment, and the volume of studies published recently regarding its effects is expanding, both quantitatively and geographically. The aim of the present review and meta-analysis is to consider the most recent evidence which assesses the effect of menu labelling regarding changes in energy consumed, ordered or selected in both real-world and experimental settings.

Design: The review included fifteen peer-reviewed, full-text articles published between 2012 and 2014. Pertinent methodological information was extracted from each of the included studies and a quality assessment scheme was applied to classify the studies, after which systematic across-study comparisons were conducted. A meta-analysis was conducted including twelve of the fifteen studies, and stratified according to type of research setting and outcome: energy consumed, ordered or selected.

Results: The rating yielded studies categorized by study quality: good ( $n 3)$, fair ( $n$ 9) and weak ( $n$ 3). Overall nine studies showed statistically significant reductions in energy consumed, ordered or selected. Three articles reported no effect of menu labelling. The meta-analysis showed statistically significant effects of menu labelling: overall energy consumed was reduced by a mean of $419 \cdot 5 \mathrm{~kJ}(100 \cdot 2 \mathrm{kcal})$ and energy ordered in real-world settings decreased by a mean of $325.7 \mathrm{~kJ}(77 \cdot 8 \mathrm{kcal})$. Conclusions: The review supports that menu labelling can effectively reduce energy ordered and consumed in the away-from-home food environment.
\end{abstract}

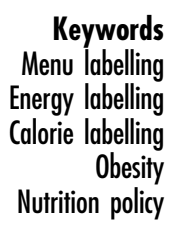

In the realm of public health, menu labelling (ML) is considered an important tool to inform consumers of the energy content of meals in the eating-out environment and to encourage favourable reformulation of menu items by the food-service industry, as a low-cost and broadreaching obesity prevention strategy ${ }^{(1,2)}$. The initiative applies the principles of nutrition labelling to foods consumed outside the home through the disclosure of energy content at the point of purchase ${ }^{(3,4)}$. ML applies to standardized food and beverage items sold at chain food establishments (with generally fifteen or more outlets). More than ever, ML is deemed necessary as the consumption of food outside the home increases ${ }^{(1,5,6)}$ and most consumers underestimate the energy content of such foods ${ }^{(7)}$, which are associated with increased energy intake $^{(8-10)}$ as well as unhealthy weight gain ${ }^{(11)}$ due to increased portion sizes and energy density. Overweight and obesity put individuals at greater risk of developing type 2 diabetes, CVD and certain cancers ${ }^{(12)}$, all of which incur great financial and social costs ${ }^{(13-15)}$. Furthermore, the disclosure of energy values at the point of purchase has overwhelming public support in several countries, including those where ML has been implemented ${ }^{(3,16-19)}$. Consumers otherwise rarely notice or access energy declarations provided by food-service establishments in any other format, including tray liners, food packaging or company websites ${ }^{(17,20)}$, despite energy being sought-after nutrition information ${ }^{(21-24)}$.

Current European Union legislation on food labelling only requires nutrition declarations on pre-packed foods and beverages. According to a modelling study conducted by the Organisation for Economic Co-operation and Development, mandatory nutrition labelling of processed foods could reduce European obesity rates by $2.5 \%$ and 
avert up to 15 million disability-adjusted life years ${ }^{(25)}$. The European Union legislation, however, does not extend to menu items prepared and served in catering outlets, despite the increase in foods eaten outside the home and strong consumer support for ML. A global survey conducted in 2011, including 250000 respondents from fifty-six countries, revealed that $80 \%$ desire ML either all the time or sometimes in fast-food establishments and full-service chain restaurants, with particularly high support for these measures in Latin America, North America and Europe ${ }^{(26)}$. Voluntary ML by the restaurant industry exists, however, in Great Britain, Northern Ireland and the Republic of Ireland ${ }^{(19,27,28)}$. The USA was the first country to implement nationwide mandatory ML in 2010, and the Food and Drug Administration issued a final rule to guide labelling for qualifying chain restaurants and food-retail establishments to sell away-from-home foods that will take effect in December $2016^{(29)}$. ML is also mandatory in some states of Australia ${ }^{(30-32)}$ and one single province in Canada ${ }^{(33)}$, while the initiative is being debated in Denmark and Asia ${ }^{(34)}$.

In addition to fast-food outlets, ML has evolved to incorporate standardized foods and beverages served in cafés, bakeries, juice bars, ice-cream parlours, tableservice restaurants, convenience stores, cinemas and supermarkets, since such establishments increasingly contribute to overall energy intake ${ }^{(5,35)}$. The expansion of ML, both geographically and with regard to the food outlets it applies to, has generated an array of new evidence as to its effects on consumer behaviour. Recent studies, often in real-world settings, add to the earlier literature, once predominated by studies conducted in experimental settings on fast-food selections in the USA.

\section{Objective}

The present review and meta-analysis aims to provide an update of the most recent evidence (studies published only between 2012 and 2014) of the effects of ML on energy consumed, ordered or selected by the general population, in both real-world and experimental settings. The review also aims to assess the importance of ML format and ML noticing by consumers as aspects impacting its effectiveness. The rationale for narrowing the inclusion dates was an attempt to capture results which may more accurately reflect consumers' response to ML as they grow accustomed to the initiative and as industry adaptation to legislation is more widespread and compliant.

For the purpose of the present article, menu labelling (ML) is defined as the prominent display of energy values appearing on menus (or food tags, retail shelf displays and other promotional material), so it clearly relates to the item and its respective price. In accordance with other ML literature, the term 'healthier' refers to lower-energy food choices, since energy content is the most important nutrition aspect in relation to overweight and obesity ${ }^{(1)}$.

\section{Methods}

\section{Literature search}

The systematic literature review was conducted in two stages between May and November 2014. The first stage was carried out by one reviewer (J.A.L.) in May-June 2014 and consisted of a systematic literature search of the MEDLINE database. Two reviewers (J.A.L. and S.L.) carried out the second stage in October-November 2014, extending the MEDLINE search to Web of Science and Science Direct databases using the same search strategy.

A structured approach was used to identify studies assessing the effects of ML on energy selected, ordered or consumed. First, the search terms 'menu board label*', 'menu label*', 'calorie label*' and 'energy label*' were applied in all databases. Then, titles and abstracts of retrieved studies were screened for relevance in accordance with the defined inclusion criteria (see below). Reference lists of identified studies were also perused for relevant additional publications. Finally, in an effort to obtain evidence beyond the USA, government agencies, such as the Food Safety Authority of Ireland, and non-government organizations known to advocate ML, such as Dietitians of Canada and the Heart Foundation of Australia, were contacted. This review is not registered in any systematic review databases.

\section{Inclusion/exclusion criteria}

Peer-reviewed articles met the inclusion criteria if they were: (i) full text; (ii) in English; (iii) published after 1 January 2012; (iv) primary studies; (v) investigating the impact of ML on purchase behaviour or purchase intentions; and (vi) with outcomes measuring the effect of ML on energy consumed, ordered or selected, as quantified $\mathrm{kJ} / \mathrm{kcal}$ differences. Energy selected referred to hypothetical choices of 'intended' purchase. Energy ordered referred to actual food and beverage items ordered from a menu, substantiated by participant recalls, purchase receipts or sales records. Energy consumed took into account uneaten portions of meals, established through either researchers weighing leftovers or participants self-reporting the uneaten portion of their meal.

Studies were excluded if they assessed only: (i) customer/participant awareness of ML; (ii) self-reported use of ML; (iii) consumer energy-based knowledge; (iv) consumer attitude towards the provision of ML; and/or (v) consumer preference for various labelling formats.

\section{Data extraction, synthesis and quality assessment}

A structured approach was applied to extract pertinent information from each of the fifteen included studies and systematic across-study comparisons were conducted based on a matrix including: year and authors; country; aim; study design; sampling; setting; type of outcome 
(including meals consumed, ordered or selected, nutrients and interpretative guidance, as well as meal type); covariates measured; results; and limitations of study design. Results from studies presented as kilocalories were converted to kilojoules based on $1 \mathrm{kcal}=4 \cdot 184 \mathrm{~kJ}$.

The quality of the included studies was assessed using a rating scheme inspired by previous reviews ${ }^{(17,36,37)}$. Articles were rated according to: study setting; sample size; extent of displaying ML; ML noticing rate; randomization (for experimental studies) or case-control match (for real-world studies); and degree of blinding (see online supplementary material, Supplemental Table 1). Two reviewers (J.A.L. and S.L.) independently rated all studies. The final scores were awarded after conferring and discussing any discrepancies, and consensus was reached.

\section{Meta-analysis}

A meta-analysis was conducted with twelve of the fifteen studies, stratified according to type of outcome: changes in energy consumed, ordered or selected. The analyses conducted compare controls (no labels) $v$. interventions presenting energy labels alone; results from intervention groups reporting the effect of interpretive guidance, such as traffic lights or physical activity equivalents (PAE), were not included in the meta-analysis. All twelve studies reporting mean and standard deviation for energy consumed, ordered or selected were included in the analysis. When such data were not reported, the corresponding authors were contacted in order to retrieve the missing data. Two studies reporting results on energy ordered $^{(38,39)}$ and one study reporting results on energy selected $^{(40)}$ were excluded due to data not being provided. No original raw data sets were available.

A random-effects meta-analysis of mean differences was conducted to assess the overall effect of ML, applying the DerSimonian-Laird estimator to evaluate the betweenstudy variance. Publication bias was assessed via funnel plots and Egger's test where appropriate, and inspected visually. Data were analysed with the statistical software $\mathrm{R}$ version 3.03 and the package meta $4 \cdot 1-0^{(41)}$. In order to quantify the effect of heterogeneity we used the $I^{2}$ statistic as a measure of the degree of inconsistency in the studies' results. The quantity $I^{2}$ describes the percentage of total variation across studies that is due to heterogeneity rather than chance ${ }^{(42)}$.

\section{Results}

\section{Search results}

The online database search identified 141 articles, fifteen of which were retrieved for full-text review (Fig. 1). Three studies considered the effects of ML on energy ordered and subsequently consumed ${ }^{(21,43,44)}$. Six studies reported on energy ordered ${ }^{(22,38,39,45-47)}$, while six assessed the effects on energy selected ${ }^{(4,16,40,48-50)}$. Seven studies were conducted in real-world settings ${ }^{(21,22,38,39,45-47)}$ and eight studies were conducted in experimental settings $^{(4,16,40,43,44,48-50)}$. Eight studies reported on the proportion of participants noticing $\mathrm{ML}^{(16,21,22,43-46,48)}$.

\section{Studies' characteristics and quality}

Overall, the effects of ML were assessed on 17859 participants spanning three countries. Despite similar aims and objectives, the studies varied greatly in design, most notably in sample size, data collection methods and ML format. Sample sizes ranged from under $50^{(39)}$ to over $2000^{(45)}$ participants. Data collection methods varied from telephone surveys collecting meal selections at random times of the day $^{(48)}$, to complete sales records from private club bistros ${ }^{(38)}$, to calculating energy consumption by obtaining calorie content and weight information from the fast-food website and deducting weighed leftovers ${ }^{(43)}$. While all studies compared the absence of ML as a control condition with the presence of $\mathrm{ML}$, the format and provision of additional contextual or interpretive guidance differed. The characteristics of the included studies are presented in Table 1 . The rating process yielded three good-quality studies, nine of fair quality and three of weak quality (see online supplementary material, Supplemental Table 2).

\section{The effects of menu labelling}

In nine of the fifteen articles reviewed, participants exposed to ML in various formats consumed, ordered or selected significantly less energy ${ }^{(4,21,22,38,43,44,47,49,50)}$ than participants not exposed to ML. Statistically significant reductions ranged from as few as $96.2 \mathrm{~kJ}(P=0.05)$ when choosing snack items ${ }^{(4)}$ to $648.5 \mathrm{~kJ}(P=0.018)$ for meals ordered at a table-service chain restaurant ${ }^{(22)}$. Only three articles reported no effects of $\mathrm{ML}^{(40,46,48)}$. The overall results are somewhat mixed, so closer attention was paid to research setting, type of outcome assessed, the extent to which participants noticed ML, ML format and sociodemographic characteristics of study participants. Where ML was partial and only applied to some items, the results of interest focused on the changes in energy consumed, ordered or selected for the labelled items. Table 2 provides a summary of results.

\section{Research setting}

Seven studies were carried out in real-world settings, one of which resulted in a $531.4 \mathrm{~kJ}(P<0.001)$ reduction in energy consumed when customers were offered a range of 'healthier' reformulated options and were exposed to ML in a cafeteria ${ }^{(21)}$ compared with no ML. The provision of ML, compared with no ML, also resulted in statistically significant reductions of energy ordered by $92 \mathrm{~kJ}$ in coffee chains $(P=0.002)^{(45)}$; between $234.3 \mathrm{~kJ}(P<0.05)^{(38)}$ and $648.5 \mathrm{~kJ}$ $(P=0.018)^{(22)}$ in table-service restaurants; and a reduction of $251 \mathrm{~kJ}(P=0.05)$ in fast-food outlets ${ }^{(47)}$. One further study 
Table 1 Characteristics of the included studies (organized by type of outcome)

\begin{tabular}{|c|c|c|c|c|c|c|}
\hline Study and country & Design & Setting & Type of ML & Subjects & Sample size & Outcomes of interest \\
\hline $\begin{array}{l}\text { Hammond et al. }(2013)^{(44)} \\
\text { Canada }\end{array}$ & $\begin{array}{l}\text { Between-group } \\
\text { experiment, RT }\end{array}$ & $\begin{array}{l}\text { Experimental setting } \\
\text { Fast-food chain menu }\end{array}$ & $\begin{array}{l}\text { - No labels } \\
\text { - Energy labels } \\
\text { - Energy labels + single TL } \\
\text { - Energy labels + multiple TL } \\
\text { (fat, Na \& sugar) }\end{array}$ & Adults & 635 & $\begin{array}{l}\text { Energy consumed } \\
\text { Energy ordered } \\
\text { Noticing ML }\end{array}$ \\
\hline $\begin{array}{l}\text { James et al. }(2014)^{(43)} \\
\text { USA }\end{array}$ & $\begin{array}{l}\text { Between-group } \\
\text { experiment, RT }\end{array}$ & $\begin{array}{l}\text { Dining area in a university } \\
\text { metabolic } \\
\text { kitchen + dining area in } \\
\text { students' residence }\end{array}$ & $\begin{array}{l}\text { - No labels } \\
\text { - Energy labels (+ RV) } \\
\text { - PAE labels }\end{array}$ & $\begin{array}{l}\text { Young adults } \\
\text { (18-30 years) }\end{array}$ & 300 & $\begin{array}{l}\text { Energy consumed } \\
\text { Energy ordered } \\
\text { Noticing ML }\end{array}$ \\
\hline $\begin{array}{l}\text { Vanderlee \& Hammond }(2013)^{(21)} \\
\text { Canada }\end{array}$ & $\begin{array}{l}\text { Between-site, exit } \\
\text { surveys }\end{array}$ & Two hospital cafeterias & $\begin{array}{l}\text { - No labels } \\
\text { - Energy labels }\end{array}$ & Adults & 1003 & $\begin{array}{l}\text { Energy consumed } \\
\text { Energy ordered } \\
\text { Noticing ML }\end{array}$ \\
\hline $\begin{array}{l}\text { Auchincloss et al. (2013) } \\
\text { USA }\end{array}$ & $\begin{array}{l}\text { Between-city, cross- } \\
\text { sectional }\end{array}$ & $\begin{array}{l}\text { Seven outlets, table- } \\
\text { service restaurant }\end{array}$ & $\begin{array}{l}\text { - No labels } \\
\text { - Energy labels }\end{array}$ & Adults & 648 & $\begin{array}{l}\text { Energy ordered } \\
\text { Noticing ML }\end{array}$ \\
\hline $\begin{array}{l}\text { Elbel et al. }(2013)^{(46)} \\
\text { USA }\end{array}$ & $\begin{array}{l}\text { Difference-in- } \\
\text { differences }\end{array}$ & $\begin{array}{l}\text { Twenty-three outlets, fast- } \\
\text { food chains }\end{array}$ & $\begin{array}{l}\text { - No labels (pre-legislation \& } \\
\text { control) } \\
\text { - Energy labels (post-legislation) }\end{array}$ & Adults & 2083 & $\begin{array}{l}\text { Energy ordered } \\
\text { Noticing ML }\end{array}$ \\
\hline $\begin{array}{l}\text { Krieger et al. (2013) } \\
\text { USA }\end{array}$ & $\begin{array}{l}\text { Pre-post-post } \\
\text { cross-sectional } \\
\text { study, exit surveys }\end{array}$ & $\begin{array}{l}\text { Forty popular fast-food } \\
\text { chain + ten coffee chain } \\
\text { locations }\end{array}$ & $\begin{array}{l}\text { - No labels (baseline) } \\
\text { - Energy labels }(6 \text { months } \\
\text { post-legislation) } \\
\text { - Energy labels (18 months post- } \\
\text { legislation) }\end{array}$ & Aged $\geq 14$ years & $6125+1200$ & $\begin{array}{l}\text { Energy ordered } \\
\text { Noticing ML }\end{array}$ \\
\hline $\begin{array}{l}\text { Brissette et al. }(2013)^{(47)} \\
\text { USA }\end{array}$ & $\begin{array}{l}\text { Between-group } \\
\text { cross-sectional } \\
\text { survey }\end{array}$ & $\begin{array}{l}\text { Thirty-one outlets, fast-food } \\
\text { chains }\end{array}$ & $\begin{array}{l}\text { - No labels } \\
\text { - Energy labels }\end{array}$ & Adults & 1094 & Energy ordered \\
\hline $\begin{array}{l}\text { Ellison et al. }(2013)^{(39)} \\
\text { USA }\end{array}$ & $\begin{array}{l}\text { Between-group } \\
\text { experiment, RT }\end{array}$ & $\begin{array}{l}\text { University campus table- } \\
\text { service restaurant }\end{array}$ & $\begin{array}{l}\text { - No labels } \\
\text { - Energy labels } \\
\text { - Energy labels + single TL }\end{array}$ & Adults & 138 & Energy ordered \\
\hline $\begin{array}{l}\text { Holmes et al. }(2013)^{(38)} \\
\text { USA }\end{array}$ & $\begin{array}{l}\text { Between-group } \\
\text { longitudinal } \\
\text { experiment }\end{array}$ & $\begin{array}{l}\text { Private club family-style } \\
\text { restaurant }\end{array}$ & $\begin{array}{l}\text { - No labels } \\
\text { - Energy labels + fat labels } \\
\text { - Healthy symbol labels } \\
\text { - Nutrition bargain price score }\end{array}$ & $\begin{array}{l}\text { Children }(1-13 \\
\text { years) }\end{array}$ & 1275 & Energy ordered \\
\hline $\begin{array}{l}\text { Dodds et al. }(2014)^{(48)} \\
\text { Australia }\end{array}$ & $\begin{array}{l}\text { Between-group } \\
\text { experiment, RCT }\end{array}$ & $\begin{array}{l}\text { Telephone survey } \\
\text { Typical fast-food menu }\end{array}$ & $\begin{array}{l}\text { - No labels } \\
\text { - Energy labels + RV } \\
\text { - Energy labels + RV + TL }\end{array}$ & $\begin{array}{l}\text { Parent/child } \\
\text { (3-12 years) } \\
\text { pairs }\end{array}$ & 329 & $\begin{array}{l}\text { Energy selected } \\
\text { Noticing ML }\end{array}$ \\
\hline $\begin{array}{l}\text { Liu et al. }(2012)^{(16)} \\
\text { USA }\end{array}$ & $\begin{array}{l}\text { Between-group } \\
\text { experiment, } \mathrm{RCT}\end{array}$ & $\begin{array}{l}\text { Online survey } \\
\text { Family-style restaurant } \\
\text { inspired menus }\end{array}$ & $\begin{array}{l}\text { - No labels } \\
\text { - Energy labels + RV } \\
\text { - Energy labels + RV + ranked } \\
\text { - Energy labels + RV + ranked + } \\
\text { colour coded }\end{array}$ & Adults & 418 & $\begin{array}{l}\text { Energy selected } \\
\text { Noticing ML }\end{array}$ \\
\hline $\begin{array}{l}\text { Dowray et al. }(2013)^{(50)} \\
\text { USA }\end{array}$ & $\begin{array}{l}\text { Between-group } \\
\text { experiment, RCT }\end{array}$ & $\begin{array}{l}\text { Online survey } \\
\text { Fast-food inspired menu }\end{array}$ & $\begin{array}{l}\text { - No labels } \\
\text { - Energy labels } \\
\text { - Energy labels + PAE (in minutes) } \\
\text { - Energy labels + PAE (in miles) }\end{array}$ & Adults & 802 & Energy selected \\
\hline
\end{tabular}


resulted in 539.7 fewer $\mathrm{kJ}(P=0.033)$ being ordered at a table-service restaurant for main meals, but no statistically significant changes were observed for 'extras' that were not consistently labelled ${ }^{(39)}$. Only one real-world study showed ML to have no statistically significant impact ${ }^{(46)}$.

Eight studies were conducted in experimental settings where consumers participated online, by post, by telephone or in laboratory settings. Two studies showed that the provision of ML on fast-food menus significantly reduced energy consumed by $397.5 \mathrm{~kJ}(P=0.048)^{(44)}$ and $200.8-405.8 \mathrm{~kJ}(P=0.04)$ across ML formats ${ }^{(43)}$. Of the remaining six studies, three resulted in overall statistically significant reductions in energy selected when participants were presented with ML on fast-food menus: $510.4 \mathrm{~kJ}$ $(P<0.05)^{(49)}$ and $398.1-811.7 \mathrm{~kJ}(P=0.02)^{(50)}$; or on a snack menu: $96 \cdot 2-146 \cdot 4 \mathrm{~kJ}(P=0 \cdot 02)^{(4)}$. One other study showed a statistically significant reduction of $644.3 \mathrm{~kJ}$ $(P=0.013)$ for a meal selected in a family-style restaurant with a ranked energy-label condition (although other ML formats tested resulted in statistically non-significant energy reductions) ${ }^{(16)}$. ML had no impact in the remaining two studies based on fast-food selections ${ }^{(40,48)}$.

\section{Energy consumed, ordered or selected}

All three studies measuring energy consumption reported statistically significant overall energy reductions $(200 \cdot 8-535 \cdot 6 \mathrm{~kJ})^{(21,43,44)}$. Three of six studies measuring the effects of ML on energy ordered resulted in overall statistically significant decreases $(234 \cdot 3-631 \cdot 8 \mathrm{~kJ})^{(22,38,47)}$. Another two studies resulted in statistically significant reductions in energy ordered for energy-labelled main meals, but not partially labelled 'extras'(39), and for coffee chains, but not food chains ${ }^{(45)}$. Three of six studies assessing the effects of ML on energy selected resulted in overall statistically significant reductions for meals $(389 \cdot 1-711 \cdot 3 \mathrm{~kJ})^{(49,50)}$ and snack selections $(129 \cdot 7 \mathrm{~kJ})^{(4)}$.

\section{Noticing of menu labelling by consumers}

Eight of the included studies reported on the rate of noticing energy information on menus. ML had no statistically significant impact where less than $70 \%$ of participants noticed the information ${ }^{(45,46)}$. The remaining studies all reported a high ML noticing rate ( $\geq 70 \%)$; of these, three studies reported statistically significant reductions in energy ordered and consumed ${ }^{(21,43,44)}$, one study reported a statistically significant reduction in energy ordered ${ }^{(22)}$ and two studies reported statistically significant reductions in energy selected ${ }^{(16,48)}$.

\section{Menu-labelling format}

A number of studies also tested the effects of different ML formats which offered interpretive or contextual guidance. The most common variation was the addition of traffic light colour coding to help consumers interpret if the menu item was low (green), medium (amber) or high (red) in energy. Traffic lights enhanced the noticeability 


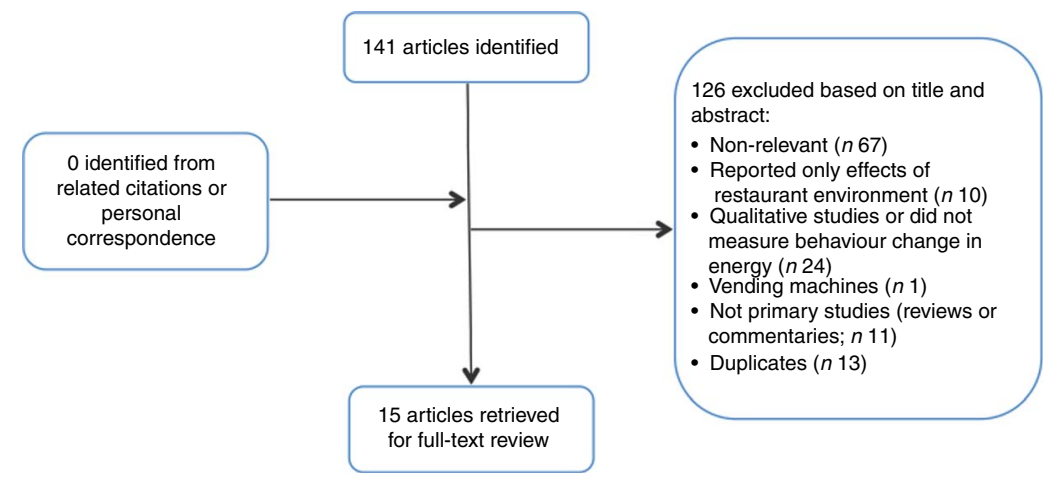

Fig. 1 Flow diagram of the literature search process

of $\mathrm{ML}^{(44,48)}$, facilitated comprehension of energy information $^{(39,49)}$, and in some instances significantly reduced total energy selected by $497.9 \mathrm{~kJ}(P<0.05)^{(49)}$ or energy ordered for main meals by $539.7 \mathrm{~kJ}(P=0.033)^{(39)}$ compared with no ML.

The use of PAE, which present energy information in terms of how much physical activity is required to expend the energy content of a specified menu item, was also effective. ML formats with PAE significantly reduced energy by $96.2 \mathrm{~kJ}(P=0.05)$ when selecting a snack ${ }^{(4)}$, and by $811.7 \mathrm{~kJ}(P=0.0007)$ when selecting a fast-food meal $^{(50)}$, compared with no ML. The use of PAE also resulted in significantly lower energy ordered $(-581.6 \mathrm{~kJ}$, $P=0.002)$ and consumed $(-405.8 \mathrm{~kJ}, \quad P=0.01)$ for a fast-food lunch compared with no $\mathrm{ML}^{(43)}$.

Reference values (RV) offer contextual guidance as to how the energy content of menu items compares to a full day's energy requirement, and appear in statements such as 'The average adult daily energy intake is $8700 \mathrm{~kJ}$ '. Five experimental studies explicitly included RV in their ML formats, one of which compared the effects of "energy labelling' with 'energy labelling with RV'. This study showed that RV enhanced the effects of energy labelling for energy selected, that it was the most effective of all ML formats and was rated by participants as the most 'understandable, ${ }^{,(4)}$. The other four studies tested ML with RV against other formats. Two of these studies showed that ML + RV significantly reduced energy selected compared with no $\mathrm{ML}^{(43,49)}$, while one showed ML + RV had no statistically significant impact unless the menu items were also ranked according to ascending energy content ${ }^{(16)}$; one study showed RV had no impact at all ${ }^{(48)}$.

\section{Sociodemographic differences}

No detailed analyses were conducted, but it appears that variances in $\mathrm{BMI}^{(16,21,49)}$, ethnicity ${ }^{(21,45,47)}$, age (21,45,47,49) $^{(21,45,45}$ and socio-economic status ${ }^{(21,45,47,49)}$ did not substantially influence the degree of effectiveness of ML. There was a tendency for those who have an interest in health, and were self-reported 'users' of labelling when purchasing food, to be statistically significantly more attentive to $\mathrm{ML}^{(21,40,47)}$. In one study, however, the level of 'interest in health' had no impact ${ }^{(49)}$, and another study showed those who were least health conscious to be statistically significantly more responsive to energy information ${ }^{(39)}$. Females were found to be statistically significantly more attentive to ML compared with males in two studies ${ }^{(21,45)}$, although another two studies reported no statistically significant differences between genders ${ }^{(49,50)}$.

\section{Meta-analysis findings}

The meta-analysis showed that the effect of ML was statistically significant for all outcomes measured. For studies measuring energy consumption, the overall estimated effect of ML was a mean reduction of 419.50 (95\% CI -613.25, -225.76) kJ ( $P<0 \cdot 0001$; Fig. 2). Studies measuring energy consumed showed no statistically significant heterogeneity.

For studies measuring energy ordered conducted in real-world settings, the effect of ML was estimated to be a mean reduction of 325.66 (95\% CI $-508.60,-142.71) \mathrm{kJ}$ $(P=0.0005)$, with significant heterogeneity $\left(I^{2}=63.8 \%\right.$; $P=0.026 ; n$ 5; Fig. 3). When studies conducted in experimental settings were included, ML reduced the overall mean energy ordered by an estimated 313.16 (95\% CI $-453 \cdot 14,-173 \cdot 19) \mathrm{kJ}(P<0 \cdot 0001)$ and heterogeneity was no longer statistically significant (Fig. 4).

For studies assessing the effect of ML on energy selected, the estimated effect of ML was a mean reduction of $201.71(95 \% \mathrm{CI}-343.66,-59.76) \mathrm{kJ}(P=0.005)$, with significant heterogeneity $\left(I^{2}=60 \cdot 2 \% ; P=0.028 ; n\right.$; Fig. 5$)$.

No publication bias was detected.

\section{Discussion}

Consumption of food outside the home is becoming more frequent ${ }^{(1,5,6)}$ and since this practice is associated with increased energy intake ${ }^{(8-10)}$ and unhealthy weight gain $^{(11)}$, it poses challenges of public health concern. The current review and meta-analysis aimed to assess whether ML is effective in reducing energy selected, ordered or consumed in both real-world and experimental settings, 


\begin{tabular}{|c|c|c|c|c|}
\hline Study & Intervention & Design & Rating & Results \\
\hline $\begin{array}{l}\text { Hammond } \\
\text { et al. } \\
(2013)^{(44)}\end{array}$ & $\begin{array}{l}\text { Compared energy ordered and consumed for a } \\
\text { meal from one of four menus: } \\
\text { - No labels } \\
\text { - Energy labels } \\
\text { - Energy labels + single TL } \\
\text { - Energy labels + multiple TL (fat, Na \& sugar) }\end{array}$ & $\begin{array}{l}\text { Between-group } \\
\text { experiment, RT }\end{array}$ & Good & $\begin{array}{l}\text { - Energy consumed decreased with presence of energy labels } v \text {. no labels }(-397.5 \mathrm{~kJ} \text {, } \\
P=0.048) \text {. No differences were registered for other ML conditions } \\
\text { - No difference between energy ordered between ML conditions } \\
\text { - Recall of energy information was higher for energy labels }(72 \%, P<0.001) \text { and energy } \\
\text { labels }+\mathrm{TL}(71 \%, P<0.001) \mathrm{v} \text {. energy labels + multiple TL condition }(49 \%)\end{array}$ \\
\hline $\begin{array}{l}\text { James et al. } \\
\quad(2014)^{(43)}\end{array}$ & $\begin{array}{l}\text { Compared energy ordered and consumed for a } \\
\text { lunch selected from one of three menus: } \\
\text { - No labels } \\
\text { - Energy labels } \\
\text { - Exercise labels }\end{array}$ & $\begin{array}{l}\text { Between-group } \\
\text { experiment, RT }\end{array}$ & Good & $\begin{array}{l}\text { - Energy consumed decreased with presence of energy and exercise labels }(-200.8 \text { to } \\
-405.8 \mathrm{~kJ}, P=0.04) \text {. Exercise labels had the strongest effect } v \text {. no labels }(P=0.01) \\
\text { - Energy ordered decreased with presence of energy and exercise labels }(P=0.008) \text {. } \\
\text { Exercise labels had the strongest effect } v \text {. no labels }(P=0.002) \\
\text { - } 90.9 \% \text { noticed energy labels and } 91.1 \% \text { noticed exercise labels }\end{array}$ \\
\hline $\begin{array}{l}\text { Vanderlee \& } \\
\text { Hammond } \\
(2013)^{(21)}\end{array}$ & $\begin{array}{l}\text { Compared energy ordered and consumed from } \\
\text { two different sites: } \\
\text { - No labels (some 'healthy' items denoted with } \\
\text { a symbol) } \\
\text { - Energy labels (reformulated 'healthier' options } \\
\text { denoted with a symbol) }\end{array}$ & $\begin{array}{l}\text { Between-site, exit } \\
\text { surveys }\end{array}$ & Fair & $\begin{array}{l}\text { - Energy consumed decreased by } 21 \% \text { from } 2355.6 \text { to } 1820 \mathrm{~kJ} \text { with presence of energy } \\
\text { labels } v \text {. no labels }(P<0.001) \\
\text { - Energy ordered decreased from } 2610.8 \text { to } 2092 \mathrm{~kJ} \text { in presence of energy labels } \mathrm{v} \text {. no } \\
\text { labels }(P<0.001) \\
\text { - } 79.5 \% \text { noticed } \mathrm{ML} \text { at intervention site; } 36.2 \% \text { noticed the healthy logo at control site }\end{array}$ \\
\hline $\begin{array}{l}\text { Auchincloss } \\
\text { et al. } \\
(2013)^{(22)}\end{array}$ & $\begin{array}{l}\text { Compared energy ordered from: } \\
\text { - Five sites with no labels } \\
\text { - Two sites with energy labels }\end{array}$ & $\begin{array}{l}\text { Between-city cross- } \\
\text { sectional study }\end{array}$ & Fair & $\begin{array}{l}\text { - Energy ordered at energy labels sites was lower for both foods }(P=0.02) \text { and non- } \\
\text { alcoholic drinks }(P=0.001) \text {. Differences persisted after adjustment for confounders for } \\
\text { both foods }(P=0.013) \text { and non-alcoholic drinks }(P=0.035) \\
\text { - } 76 \% \text { noticed ML at energy label sites }\end{array}$ \\
\hline $\begin{array}{l}\text { Elbel et al. } \\
\qquad(2013)^{(46)}\end{array}$ & $\begin{array}{l}\text { Compared energy ordered from twenty-three } \\
\text { sites in two cities, pre- and post-labelling: } \\
\text { - No labels (control) } \\
\text { - No labels (pre-legislation) } \\
\text { - Energy labels (post-legislation) }\end{array}$ & $\begin{array}{l}\text { Difference-in- } \\
\text { differences design }\end{array}$ & Fair & $\begin{array}{l}\text { - No net impact of } M L \text { on total energy ordered, neither for food nor beverage orders } \\
\text { considered separately } \\
\text { - Pre-post } M L \text { noticing in city with } M L \text { legislation increased from } 9 \% \text { to } 38 \% \\
\text { respectively, and remained unchanged in city with no ML legislation (14\%). Difference- } \\
\text { in-differences impact }=33 \text { percentage points }(P<0.001)\end{array}$ \\
\hline $\begin{array}{l}\text { Krieger et al. } \\
\quad(2013)^{(45)}\end{array}$ & $\begin{array}{l}\text { Compared energy ordered from fifty fast-food and } \\
\text { coffee chain outlets: } \\
\text { - No labels (baseline, prior to ML legislation) } \\
\text { - Energy labels ( } 6 \text { months post-legislation) } \\
\text { - Energy labels (18 months post-legislation) }\end{array}$ & $\begin{array}{l}\text { Pre-post-post cross- } \\
\text { sectional study, exit } \\
\text { surveys }\end{array}$ & Good & $\begin{array}{l}\text { - No changes in energy ordered at } 4-6 \text { months post-legislation } \\
\text { - Energy ordered decreased in both fast-food outlets (trend, } P=0.06) \text { and coffee chain } \\
\text { outlets (92 kJ, } P=0.002) \text { at } 18 \text { months post-legislation } \\
\text { - ML noticing was } 58.3 \% \text { and } 61.7 \% \text { at } 6 \text { and } 18 \text { months post-legislation respectively in } \\
\text { fast-food outlets. ML noticing was } 31.2 \% \text { and } 30.0 \% \text { respectively in coffee chain } \\
\text { outlets }\end{array}$ \\
\hline $\begin{array}{l}\text { Brissette et al. } \\
\quad(2013)^{(47)}\end{array}$ & $\begin{array}{l}\text { Compared energy ordered from: } \\
\text { - Fourteen fast-food sites with no labels } \\
\text { - Seventeen fast-food sites with energy labels }\end{array}$ & $\begin{array}{l}\text { Between-group cross- } \\
\text { sectional survey }\end{array}$ & Fair & $\begin{array}{l}\text { - Energy ordered decreased from } 3965 \text { to } 3715.8 \mathrm{~kJ}(P=0.05) \text { in sites with energy labels } \\
V \text {. sites with no labelling }\end{array}$ \\
\hline $\begin{array}{l}\text { Ellison et al. } \\
\quad(2013)^{(39)}\end{array}$ & $\begin{array}{l}\text { Compared energy ordered for three ML conditions: } \\
\text { - No labels } \\
\text { - Energy labels } \\
\text { - Energy labels }+ \text { single TL }\end{array}$ & $\begin{array}{l}\text { Between-group } \\
\text { experiment, RT }\end{array}$ & Weak & $\begin{array}{l}\text { - No differences in total energy ordered between } \mathrm{ML} \text { conditions } \\
\text { - For entrées, the energy ordered in the energy labels }+ \text { single TL was lower than in the } \\
\text { other conditions }(-539.7 \mathrm{~kJ}, P=0.033) \text {. For extras, no differences in energy ordered } \\
\text { were registered between ML conditions }\end{array}$ \\
\hline $\begin{array}{l}\text { Holmes et al. } \\
\qquad(2013)^{(38)}\end{array}$ & $\begin{array}{l}\text { Compared energy ordered for children's meals. } \\
\text { Each ML condition was displayed for } 2 \text { months } \\
\text { at the same site: } \\
\text { - No labels } \\
\text { - Energy labels + fat labels }\end{array}$ & $\begin{array}{l}\text { Between-group } \\
\text { longitudinal } \\
\text { experiment }\end{array}$ & Fair & $\begin{array}{l}\text { - Energy ordered for combo meals decreased for all ML conditions }(234.3 \mathrm{~kJ}, P<0.05) v \text {. } \\
\text { the no labels condition }\end{array}$ \\
\hline
\end{tabular}


Table 2 Continued

\begin{tabular}{|c|c|c|c|c|}
\hline Study & Intervention & Design & Rating & Results \\
\hline & $\begin{array}{l}\text { - Healthy symbol labels } \\
\text { - Nutrition bargain price score } \\
\text { - Only combo meals were labelled to test the effects } \\
\text { in substitution patterns ( } 35.5 \% \text { ( } n 453) \text { were } \\
\text { combo meals) }\end{array}$ & & & \\
\hline $\begin{array}{l}\text { Dodds et al. } \\
\qquad(2014)^{(48)}\end{array}$ & $\begin{array}{l}\text { Compared energy selected from one of three ML } \\
\text { conditions (parent/child): } \\
\text { - No labels } \\
\text { - kJ labels (with RV) } \\
\text { - kJ labels (with RV) + TL }\end{array}$ & $\begin{array}{l}\mathrm{RCT} \text {, between-group } \\
\text { experiment }\end{array}$ & Fair & $\begin{array}{l}\text { - No differences in total energy selected for adults or children } \\
\text { - ML noticing was significantly higher for the TL condition }(96 \%) \text { than for the kJ labels } \\
\text { condition }(82 \% ; P=0.001)\end{array}$ \\
\hline $\begin{array}{l}\text { Liu et al. } \\
\qquad(2012)^{(16)}\end{array}$ & $\begin{array}{l}\text { Compared energy selected for a meal from one of } \\
\text { four ML conditions: } \\
\text { - No labels } \\
\text { - Energy labels (with RV) } \\
\text { - Energy labels (with RV), ranked } \\
\text { - Energy labels (with RV), ranked + } \\
\text { colour coded }\end{array}$ & $\begin{array}{l}\mathrm{RCT} \text {, between-group } \\
\text { experiment }\end{array}$ & Fair & $\begin{array}{l}\text { - No differences in absolute total energy selected between } \mathrm{ML} \text { conditions } \\
\text { - When adjusted for covariates, participants exposed to the ranked energy condition } \\
\text { selected a lower energy amount than participants in the no labels condition }(-644.3 \mathrm{~kJ} \text {, } \\
P=0.013) \\
\text { - } 93.1 \% \text { noticed the ML }\end{array}$ \\
\hline $\begin{array}{l}\text { Dowray et al. } \\
(2013)^{(50)}\end{array}$ & $\begin{array}{l}\text { Compared energy selected from one of four ML } \\
\text { conditions: } \\
\text { - No labels } \\
\text { - Energy labels } \\
\text { - Energy labels + PAE (min) } \\
\text { - Energy labels + PAE (distance) }\end{array}$ & $\begin{array}{l}\mathrm{RCT} \text {, between-group } \\
\text { experiment }\end{array}$ & Fair & $\begin{array}{l}\text { - Total energy selected was lower for all } \mathrm{ML} \text { conditions }(-389.1 \text { to }-811.7 \mathrm{~kJ}, P=0.02) \text {. } \\
\text { Pairwise comparisons showed significantly lower energy was selected in the energy } \\
\text { labels + PAE (distance) condition } v \text {. no labels }(P=0.0007) \\
\text { - For burgers, energy selected was lower for all } \mathrm{ML} \text { conditions }(P=0.03) \text {. Pairwise } \\
\text { comparisons showed significantly lower energy was selected in the energy } \\
\text { labels + PAE (distance) condition } v \text {. no labels }(P=0.001) \\
\text { - For side orders, energy selected was lower for all ML conditions }(P=0.02) \text {. Pairwise } \\
\text { comparisons showed significantly lower energy was selected in the energy labels + } \\
\text { PAE (distance) condition } v \text {. no labels }(P=0.007)\end{array}$ \\
\hline $\begin{array}{l}\text { Morley et al. } \\
\quad(2013)^{(49)}\end{array}$ & $\begin{array}{l}\text { Compared energy selected from one of five ML } \\
\text { conditions: } \\
\text { - No labels } \\
\text { - kJ labels (with RV) } \\
\text { - kJ labels (with RV) +\%DI } \\
\text { - kJ labels (with RV) + TL } \\
\text { - kJ labels (with RV) + TL + \%DI }\end{array}$ & $\begin{array}{l}\mathrm{RCT} \text {, between-group } \\
\text { experiment }\end{array}$ & Fair & $\begin{array}{l}\text { - Energy selected was lower for participants exposed to energy labels and energy } \\
\text { labels }+\mathrm{TL}(-510.4 \mathrm{~kJ}, P<0.05 \text { for both) }\end{array}$ \\
\hline $\begin{array}{l}\text { Pang \& } \\
\text { Hammond } \\
(2013)^{(4)}\end{array}$ & $\begin{array}{l}\text { Compared energy selected from one of four ML } \\
\text { conditions: } \\
\text { - No labels } \\
\text { - Energy labels } \\
\text { - Energy labels + RV } \\
\text { - Energy labels + PAE (min) }\end{array}$ & $\begin{array}{l}\mathrm{RCT} \text {, between-group } \\
\text { experiment }\end{array}$ & Weak & $\begin{array}{l}\text { - For snacks, energy selected was lower for all } \mathrm{ML} \text { conditions } v \text {. no labels }(1393.3 \mathrm{~kJ}) \text { : } \\
\text { energy labels }(-144.3 \mathrm{~kJ}, P=0.02) \text {; energy labels + RV }(-156.9 \mathrm{~kJ}, P=0.01) \text {; and } \\
\text { energy labels + PAE (-90 kJ, } P=0.05)\end{array}$ \\
\hline $\begin{array}{l}\text { Roseman et al. } \\
(2013)^{(40)}\end{array}$ & $\begin{array}{l}\text { Compared energy selected from one of two ML } \\
\text { conditions: } \\
\text { - No labels } \\
\text { - Energy labels }\end{array}$ & $\begin{array}{l}\mathrm{RCT} \text {, between-group } \\
\text { experiment }\end{array}$ & Weak & - No differences in energy selected between ML conditions \\
\hline
\end{tabular}

TL, traffic light; ML, menu labelling; RV, reference values; PAE, physical activity equivalent; \%DI, \%DI, percentage of daily intake; RT, randomized trial; RCT, randomized controlled trial. 


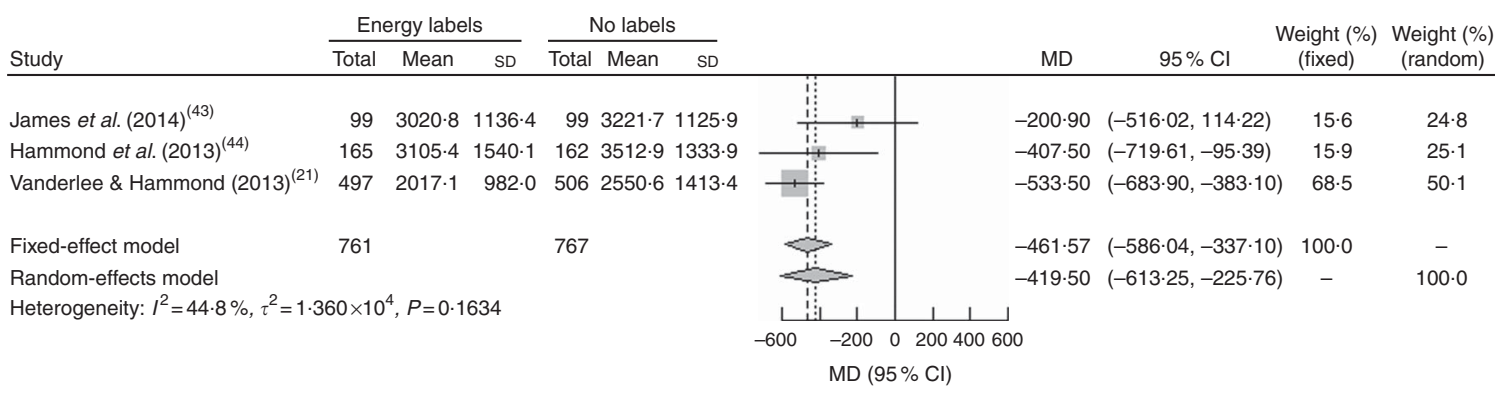

Fig. 2 Change in energy consumed associated with menu labelling compared with no menu labelling (all energy change units in $\mathrm{kJ}$ ). The study-specific mean difference (MD) and $95 \% \mathrm{Cl}$ are represented by the black dot square and horizontal line, respectively; the area of the grey square is proportional to the specific-study weight to the overall meta-analysis. The centre of the diamond represents the pooled MD and its width represents the pooled $95 \% \mathrm{Cl}$

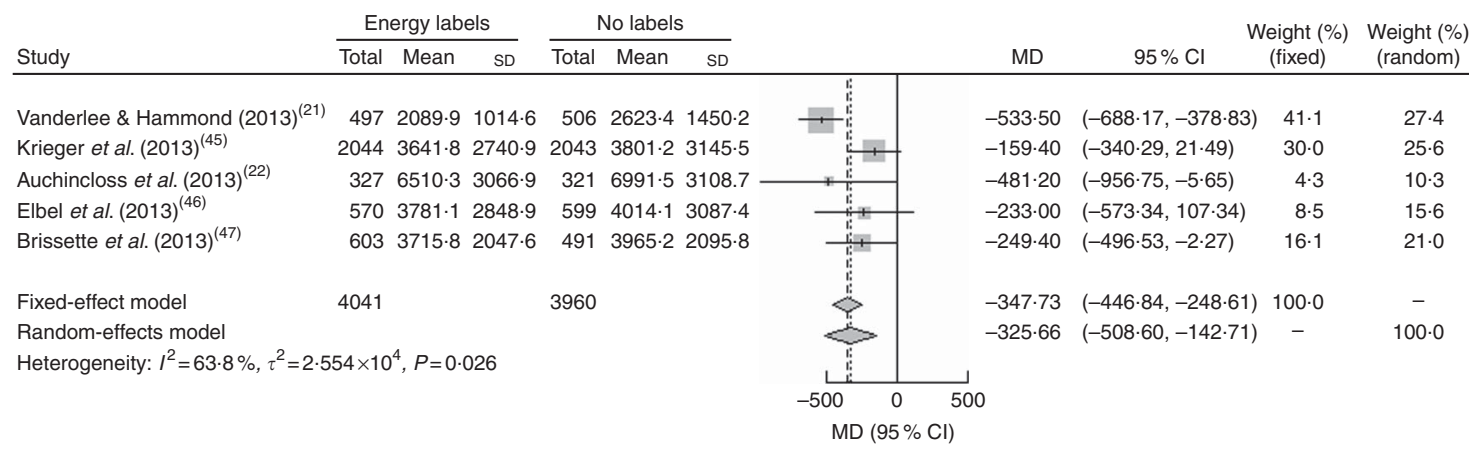

Fig. 3 Change in energy ordered (per meal or transaction) associated with menu labelling compared with no menu labelling in studies conducted in real-world settings (all energy change units in $\mathrm{kJ}$ ). The study-specific mean difference (MD) and $95 \% \mathrm{Cl}$ are represented by the black dot square and horizontal line, respectively; the area of the grey square is proportional to the specific-study weight to the overall meta-analysis. The centre of the diamond represents the pooled MD and its width represents the pooled $95 \% \mathrm{Cl}$

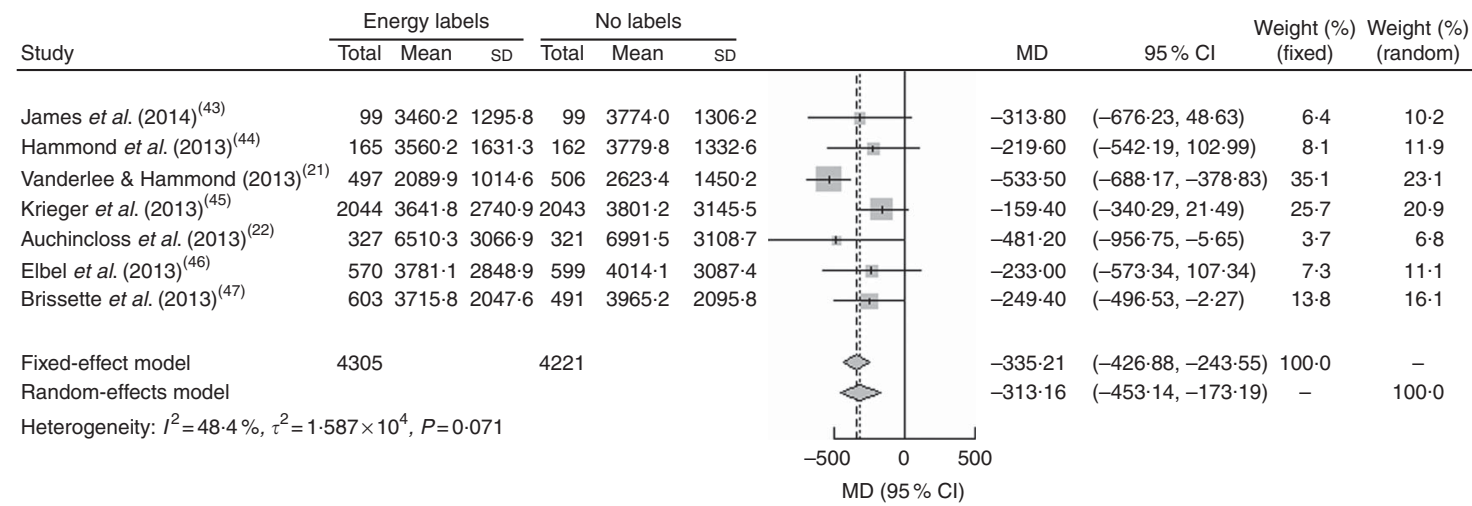

Fig. 4 Change in energy ordered (per meal or transaction) associated with menu labelling compared with no-menu labelling (all studies measuring energy ordered; all energy change units in $\mathrm{kJ}$ ). The study-specific mean difference (MD) and $95 \% \mathrm{Cl}$ are represented by the black dot square and horizontal line, respectively; the area of the grey square is proportional to the specific-study weight to the overall meta-analysis. The centre of the diamond represents the pooled MD and its width represents the pooled $95 \% \mathrm{Cl}$

and to assess the importance of ML noticing, according to the most recent published literature.

\section{Is menu labelling effective?}

Previous reviews cast doubt over the effectiveness of ML in changing consumer behaviour with regard to reducing energy ordered and/or consumed. A review from 2008, considering six studies published between 1976 and 2006, concluded that the effects may be limited in magnitude ${ }^{(51)}$. Another review from 2012, based on seven studies published between 2008 and 2011, suggested that energy labelling had 'no effect or only a modest effect' ${ }^{\text {'(37). }}$. A review from 2014, including thirty-one studies from 2007 to 2013, concluded that 'calorie labels do not have the desired effect ${ }^{(52)}$. More recently in 2015, a review and 


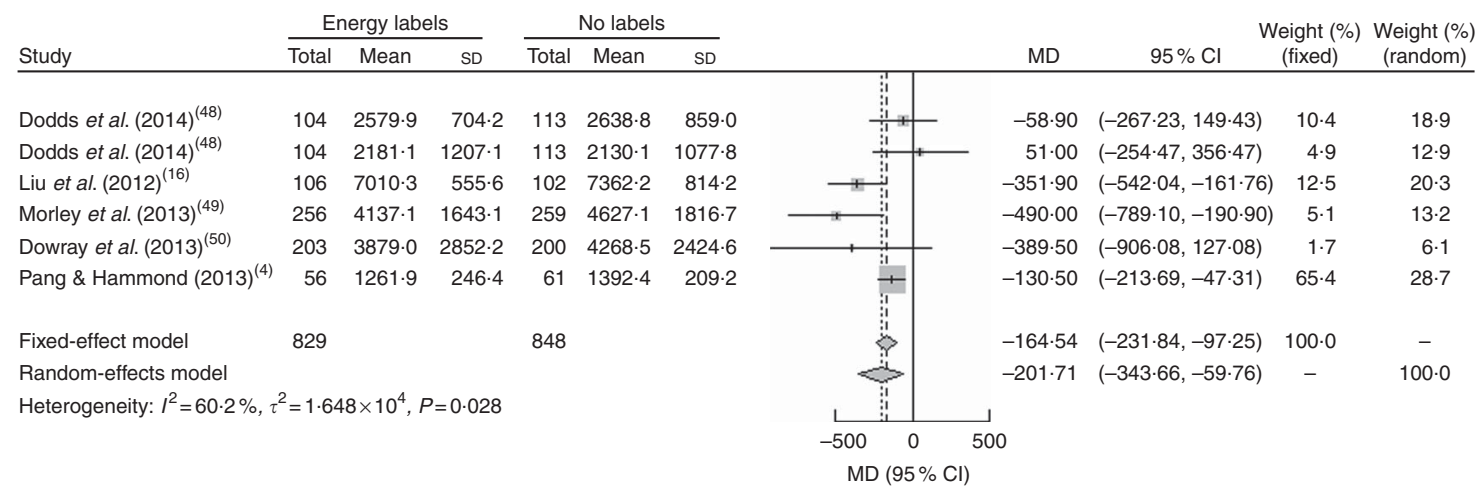

Fig. 5 Change in energy selected associated with menu labelling compared with no menu labelling (all energy change units in kJ). The study-specific mean difference (MD) and $95 \% \mathrm{Cl}$ are represented by the black dot square and horizontal line, respectively; the area of the grey square is proportional to the specific-study weight to the overall meta-analysis. The centre of the diamond represents the pooled MD and its width represents the pooled $95 \% \mathrm{Cl}$

meta-analysis by Long et al., including nineteen studies spanning from 2008 to 2013, found a small but statistically significant energy reduction in energy ordered per meal, but this was associated with statistically significant heterogeneity across studies ${ }^{(53)}$. Despite no restrictions on the published date of the studies included, only those published since 2008 were deemed acceptable, due to the eligibility criteria applied, which excluded studies with ML formats not consistent with the US federal ML laws.

The present review includes only studies published between 2012 and 2014 based on suggestions from other authors that ML may become more effective over time, as it might more accurately reflect consumers' response to ML as they grow accustomed to the initiative and as industry adaptation to legislation becomes more consistent, widespread and compliant ${ }^{(18,19,21,37,45,51,54-57)}$. Further, the present review and meta-analysis take ten new primary studies into account, not included in previous reviews $^{(4,21,22,38,39,43,44,46-48)}$. A crude tally of results, based on predominantly fair- and good-quality studies, provides a more positive outlook compared with earlier reviews. Nine studies showed statistically significant reductions in energy consumed, ordered or selected. Four studies reported positive effects, depending on consumer characteristics, type of establishment or the format of ML. Only three articles reported no effect of ML. Furthermore, the meta-analysis confirmed that ML is effective in reducing energy consumed and energy ordered, particularly in real-world settings, as well as reducing energy selected in experimental settings.

This positive trend may be attributable to new studies emerging from countries other than the USA where ML policy was initially strongly opposed by industry and gained negative press ${ }^{(58-62)}$. Furthermore, implementation of ML legislation was sporadic and inconsistent across jurisdictions, pending national legislation ${ }^{(63)}$, and practical utility and policy compliance were low ${ }^{(64)}$. The US scenario can be contrasted to the swift implementation of ML in New South Wales, Australia, where the policy was shaped by a consultation with stakeholders, while implementation was supported with extensive social marketing and educational efforts, and industry was provided with implementation assistance. Here, an outcome evaluation resulted in statistically significant decreases $(-518.8 \mathrm{~kJ})$ in energy ordered and $100 \%$ industry compliance to legislation, 18 months after implementation ${ }^{(18)}$.

The strengthening of the evidence over time could also be attributed to consumers now being used to see and expect ML. The notion that repeated exposure is needed for consumers to notice and understand ML is demonstrated by studies collecting multiple sets of post-labelling data. In such studies ML had a greater impact after 1 year, compared with 6 months ${ }^{(18,45,65)}$. These results, however, may also be attributable to reformulation or the addition of 'healthier' options appearing on menus as a food industry response to $\mathrm{ML}^{(66,67)}$, although some research indicates that ML has little effect on menu items' overall energy content $^{(68)}$. The positive effects of repeated exposure, or consumer familiarity with ML, are further supported by findings from studies reporting on the level of ML noticing by participants. ML had no impact where less than $70 \%$ of participants noticed the information ${ }^{(45,46)}$, but ML had a statistically significant positive impact with regard to energy ordered and/or consumed for the majority of studies where at least $70 \%$ of participants noticed the information $^{(21,22,43,44)}$. This social normalization of ML in restaurants could hence lead to a critical mass of businesses that offer the information necessary to drive industry reformulation to reduce the energy content of menu items.

\section{The effects of menu labelling in real-world and experimental settings}

Other reviews often excluded studies measuring energy hypothetically selected or studies conducted in laboratory settings ${ }^{(37,51)}$. Such studies were included in the present review since they can control variables such as ML formats 
that can be held constant for items offered, prices and portion sizes, and can more accurately capture the effects of ML $v$. no ML, while internal validity can be strengthened by randomization. Such study designs, however, do not take into account the strong influences of price (where few participants actually pay for the meal), food preferences, participant hunger/satiety level, or the social and environmental contexts of eating behaviour ${ }^{(69,70)}$. To compensate, the quality assessment scheme awarded more points to real-world studies.

Four out of seven studies conducted in real-world settings resulted in ML statistically significantly reducing overall energy ordered and consumed ${ }^{(21,22,38,47)}$. Another two real-world studies resulted in statistically significant reductions in energy ordered for energy-labelled main meals ${ }^{(39)}$ and for coffee chains ${ }^{(45)}$. This is a progressive and positive step compared with the reviews by Krieger and Saelens (2013) and Long et al. (2015), which found that only those studies conducted in experimental settings resulted in statistically significant energy reductions ${ }^{(17,53)}$. The positive impact of ML on consumer behaviour in realworld settings is further highlighted by the results of an outcome evaluation of ML implementation in New South Wales, Australia, where the median energy purchased decreased significantly by $15 \%$ from May 2011 to January $2013^{(18)}$, and by the results of the current meta-analysis which found a statistically significant reduction in energy ordered in real-world settings. Our results are further supported by a recent study conducted in dining facilities in a university residential hall - the first, to the best of our knowledge, reporting the effects of ML on BMI. In that study, prolonged exposure to prominent ML was associated with halving the likelihood of weight gain in young adults ${ }^{(65)}$. Collectively, these findings dismiss that positive outcomes are limited to experimental settings or that these results should be largely due to response bias.

\section{The effects of menu labelling in different types of outlet}

Most of the studies included in the present review were based on 'typical' fast-food menus and the majority of these resulted in statistically significant reductions of at least $251 \mathrm{~kJ}$ consumed, ordered or selected ${ }^{(43,44,47,49,50)}$. This should be considered very encouraging since the consumption of fast food is frequent, primarily due to its affordability and convenience ${ }^{(71,72)}$. The provision of point-of-purchase energy information can help overcome passive overconsumption ${ }^{(73)}$ and counter pricing incentives to 'up-size' or 'bundle'.

The present review also included studies conducted in table-service restaurants, given their increasing contribution to total energy intake ${ }^{(74,75)}$ and that their meals are high in energy, even compared with fast food ${ }^{(76,77)}$. Although most patrons appreciate energy information on table-service restaurant menus ${ }^{(16,19,74)}$, the impact on meal choices was not consistent in the current review ${ }^{(16,22,38,39)}$. This may reflect attitudes towards allowing the occasional indulgence ${ }^{(74)}$, evidenced by some consumers ordering about three-quarters of the recommended average daily energy intake in a single meal ${ }^{(16,22)}$. The energy content of similar dishes served at leading family-style restaurants can vary considerably ${ }^{(44)}$, largely due to portion sizes ${ }^{(78,79)}$, where, for example, a 'small burger and fries' can range from $2008 \cdot 3$ to $4602 \cdot 4 \mathrm{~kJ}$ between chains ${ }^{(47)}$.

There were some instances when energy labelling alone reduced energy ordered by $288 \cdot 7-389 \cdot 1 \mathrm{~kJ}^{(16,39,50)}$, although these decreases were statistically insignificant. Such reductions could, however, be considered relevant in terms of public health outcomes, especially for regular out-of-home eating, since sustained energy decreases as small as about $210 \mathrm{~kJ}$ per restaurant visit can avert weight gain $^{(80,81)}$. These findings support the need for ML to extend beyond the fast-food setting into table-service/ family-style chain restaurants, to enable consumers to make within- and between-chain comparisons. Furthermore, ML could encourage chain outlets to reduce energy content through product reformulation. Introducing healthier options or reducing the energy content is a new trend in various food-service outlets, which concurred with the introduction of ML, and can save consumers hundreds of kilojoules per restaurant visit ${ }^{(66,82)}$.

\section{The effects of menu labelling on energy consumption}

Energy consumption, it could be argued, most accurately determines the effects of ML, since consumers could respond to ML by eating less ${ }^{(44)}$ and it helps control for social desirability bias ${ }^{(83)}$. All three studies measuring energy consumption resulted in statistically significant energy reductions ${ }^{(21,43,44)}$, in one case as high as $21 \%$, although in that particular study the energy-labelled menu also contained 'healthier' reformulated items compared with the control menu, which might have contributed to its impact $^{(21)}$. The meta-analysis showed a statistically significant reduction of $419.5 \mathrm{~kJ}$ in the mean energy consumed. Thus, current evidence supports that ML can contribute to obesity prevention by prompting people to choose more energy-appropriate meals or eating less.

\section{The impact of noticing menu labelling}

While the format of ML was once proposed to be a possible explanation for the mixed results as to the effect of $\mathrm{ML}^{(16,44,49)}$, the present review suggests the level of visibility or noticeability of the information as a more important factor. Earlier studies have identified that ML has both a salience effect, whereby the provision of prominent energy disclosure incites consumers to have a higher regard for health when making selections, and a learning effect, whereby consumers are better able to recall or estimate the energy content of their food and beverage choices ${ }^{(84)}$. 
The current review found evidence of the learning effect, when participants presented with ML were better able to estimate and recall the energy content of their menu choices compared with those whose menu contained no energy information ${ }^{(16,43,44)}$. Previous reviews have often neglected the importance of this factor.

\section{The effects of menu-labelling formats and reference values}

More than half the studies included in the current review tested the effects of ML offering interpretive guidance. While traffic light labelling and PAE may have enhanced noticeability of ML and improved customer understanding of the information, this did not translate to improved ML use compared with energy labelling alone. Only one of five studies testing traffic light labelling ${ }^{(39)}$ and two of three studies testing $\operatorname{PAE}^{(43,50)}$ were more effective in reducing energy than the plain disclosure of energy information. While other studies have found that traffic lights 'drew attention to' and 'facilitated understanding, ${ }^{\text {(85) }}$ in various settings and across sociodemographic $\operatorname{groups}^{(83,86)}$, and overcome barriers to ML use such as low numeracy skills and time needed to consider the information ${ }^{(46,87)}$, the colour codes can be considered 'coercive' or 'directive', which may deter their use ${ }^{(88)}$. Other studies have found PAE to be effective in reducing energy consumed or ordered ${ }^{(23,89,90)}$ by framing energy information in a more familiar and tangible way, allowing consumers to comprehend the tradeoffs between energy consumption and expenditure ${ }^{(73)}$. A difference of $251 \mathrm{~kJ}$ between items, for example, was considered trivial, but an extra 20 min of walking effectively prompted participants to consider menu options more carefully ${ }^{(73)}$. PAE, however, are more often popular with younger consumers ${ }^{(4)}$ and those of normal weight ${ }^{(47)}$, and may be considered irrelevant by the elderly or those who do not habitually partake in the illustrated physical activity ${ }^{(73)}$.

It is difficult to isolate the effects of RV from the studies considered in the present review due to considerable differences in study designs; most notably, only one tested the effects of $\mathrm{ML}+\mathrm{RV}$ compared with plain energy labelling ${ }^{(4)}$. While the review provides no consistent evidence as to the effects of $\mathrm{RV}$, a recent meta-analysis found that disclosing energy only had marginal effects, while adding contextual information in the form of RV assisted consumers to significantly reduce energy consumed by $338.9 \mathrm{~kJ}$ and selected by $280 \cdot 3 \mathrm{~kJ}^{(36)}$.

Other reviews have excluded studies where menus were only partially labelled ${ }^{(37,51)}$, whereas such studies were included in the current review. While partial labelling does not accurately capture the effects of ML in terms of an entire meal, such designs offer important insights into substitution effects and shifts in purchasing patterns between labelled and unlabelled items. The rating scheme, however, took into account the limitation of selective labelling (online supplementary material, Supplemental Table 1). When brand-name non-alcoholic drinks ${ }^{(22)}$, for example, and à la carte meals ${ }^{(38)}$ remained unlabelled, energy purchased increased for these menu items, while there was a corresponding decrease for total energy purchased ${ }^{(22)}$ and for labelled combo meals ${ }^{(38)}$ attributable to ML. All menu items therefore need to be labelled to ensure shifts in purchase patterns are fully informed.

\section{Sociodemographic aspects of menu labelling}

Sociodemographic differences such as socio-economic status, BMI, race and age had little effect on ML use, supporting the observation by Morley et al. ${ }^{(49)}$ that ML is an equitable initiative. Particularly encouraging is that low socio-economic status was earlier associated with little or no response to $\mathrm{ML}$ in studies originating from the $\mathrm{USA}^{(91)}$. The present review quells previous health disparity concerns by showing that ML can be effective across social grades.

\section{Strengths and limitations}

Mixed results for the efficacy of ML from studies conducted prior to 2012 may partly be explained by consumers not noticing or understanding the inclusion of energy values on menus, industry non-compliance, ineffective labelling presentations or limited consumer exposure to ML. The current review is, to the best of our knowledge, the first to focus exclusively on articles published in very recent years (2012-2014) and despite the narrow time period, fifteen articles still met the inclusion criteria. The potential strength of the review design thereby restricts the evidence to better reflect the evolution and progressive improvements in ML design and implementation. This limited scope can, however, introduce a bias whereby only studies with positive results of ML have been submitted and accepted for publication in more recent years.

A clear limitation of the present review, as well as previous reviews, is that several of the included studies had methodological shortcomings, such as incomplete $\mathrm{ML}^{(21,38,39)}$, medium or small sample size ${ }^{(4,16,39,40,43,48)}$, lack of case-control match ${ }^{(21,22)}$, and statistically significant differences between comparison groups not adjusted for or not reported ${ }^{(4,39,40,47)}$. Only three studies were rated as good quality.

Seven studies included in the review were conducted in real-world settings. It could be argued that results from such settings provide the strongest evidence of the effectiveness of ML, since experimental settings do not accurately reflect the complexity of the eating-out-environment where sights, sounds, smells, price and promotional influence, among other factors, affect consumer choices $^{(69)}$. While studies from experimental settings were also included in the present review, the rating criteria scheme awarded this type of setting fewer points, compared with real-world studies, and analysis of results 
was independent for both setting types to control for this limitation. The meta-analysis conducted on studies measuring energy ordered in real-world settings shows a statistically significant mean reduction of $325.6 \mathrm{~kJ}$, which contradicts the findings of the meta-analysis by Long et $a l .{ }^{(53)}$. However, only five studies were included in the present meta-analysis, there was statistically significant heterogeneity between them and one of the studies was classified as weak. Furthermore, one of the studies included offered 'healthier' reformulated options in the menus, which could have accounted for its positive impact ${ }^{(21)}$. Thus, this calls for a revision of the analysis in the near future to include emerging real-world studies measuring energy ordered.

Similarly, the consumption of energy can be argued to be the best proxy measure of ML efficacy given the extremely limited evidence available measuring changes in population weight. The present meta-analysis showed a statistically significant reduction in energy consumed, and it was based on two studies of good quality and one of fair quality. However, the scarcity of studies measuring this outcome is a limitation to the analysis and since reliable methods for measuring energy consumption are more intrusive and costly, it might be some time before enough good-quality studies are available for a follow-up analysis. Additionally, studies measuring only consumption of energy in a single meal do not allow us to rule out possible compensatory energy consumption behaviour in subsequent meals.

Reductions in energy ordered still provide valuable information in the sense that energy consumption is limited by the amount of energy ordered. Studies measuring energy selected and ordered were included in the present review, but were awarded fewer points than studies measuring energy consumed, while the outcomes were analysed separately. Energy selected as an outcome yielded the lowest rating since the absence of price and fabricated 'generic' menus are likely to affect hypothetical choices. Moreover, some hypothetical meal selections were made at random times of the day that did not correspond to a regular mealtime ${ }^{(48)}$. Still, the meta-analysis showed that the effect of ML was statistically significant regardless of the measured outcome, although it should be noted that there was statistically significant heterogeneity present in the analysis for both energy selected and energy ordered, and the number of studies included is limited for all outcomes. Furthermore, even though no publication bias was detected, these tests are generally underpowered and as such publication bias might not have been detected in our sample of studies.

More reliable research is needed to determine the impact of ML on reducing energy ordered and consumed in real-world settings. It is important for future studies to report on the level of ML awareness, the extent to which ML exists (partial or full compliance), the time of data collection relative to ML implementation, the inclusion of contextual or interpretive information, and the intensity and duration of educational and social marketing efforts undertaken to support ML introduction, to more accurately reflect potential reductions of energy consumed, ordered or selected attributable to the presence of ML. Just as the most effective format of presenting nutrition labelling on pre-packaged foods is yet to be determined ${ }^{(34)}$, further studies are required to establish the most effective way of displaying ML.

Notwithstanding that ML places the burden on the individual to choose energy-appropriate menu items and that information-based obesity prevention strategies alone have not stopped or reversed the global trend of increased population weight, it is still conceivable that ML could prevent excess energy consumption in the eating-out environment and prevent unhealthy weight gain, given the results of the current review. ML can complement other obesity prevention strategies and it provides information that is desired by consumers. It is the most sought-after nutrition information in restaurant settings, ${ }^{(92)}$ which can enhance consumers' motivation to use it. Furthermore, product reformulation and 'healthier' options as an industry response to ML can reduce energy consumption even without consumer knowledge, alleviating the individual burden.

\section{Conclusions}

The present review found that ML is effective in reducing energy ordered and consumed in real-world settings. ML was shown to be effective in various types of food-service outlet and appears to positively affect a large proportion of the population. It further provides evidence that prolonged, prominent and noticeable labelling of all menu items, preferably with reference values, is important to increase ML use by heterogeneous populations and to enable shifts in purchasing patterns guided by the prominent display of energy values. Time is needed for the food-service industry to comply with regulations and for consumers to become familiar with ML. As the eatingout environment increasingly contributes to a larger proportion of total energy intake, providing energy information at the point of purchase is essential for consumers to make informed food choices, and ML should be considered an important component in a multifaceted approach to reduce the burden of overweight and obesity.

\section{Acknowledgements}

Acknowledgements: The authors would like to thank Elin Raakvad for constructive feedback on the manuscript. Financial support: This research received no specific grant from any funding agency in the public, commercial or not-for-profit sectors. Conflict of interest: None. Authorship: J.A.L. and S.L. formulated the research 
questions, designed the study, carried out the systematic review and analysed the data for the systematic review. The two authors wrote the article. C.L.I. carried out the meta-analysis and made the meta-analysis figures. G.L.H. provided critical review and suggestions for the text and provided the final approval of the version to be published. Ethics of human subject participation: Not applicable.

\section{Supplementary material}

To view supplementary material for this article, please visit http://dx.doi.org/10.1017/S1368980015003468

\section{References}

1. New South Wales Food Authority (2010) Better Regulation Statement: Provision of Nutritional Information at Point of Sale in Standard Retail Food Outlets. Newington, NSW: NSW Food Authority.

2. Nikolaou CK, Lean ME \& Hankey CR (2014) Calorie-labelling in catering outlets: acceptability and impacts on food sales. Prev Med 67, 160-165.

3. Mah CL, Vanderlinden L, Mamatis D et al. (2013) Ready for policy? Stakeholder attitudes toward menu labelling in Toronto, Canada. Can J Public Health 104, e229-234.

4. Pang J \& Hammond D (2013) Efficacy and consumer preferences for different approaches to calorie labeling on menus. J Nutr Educ Behav 45, 669-675.

5. Andersen V (2014) Folkesundhed: Fastfood er da fedt-eller er det? Copenhagen: Mandag Morgen.

6. National Restaurant Association (2014) Facts at a Glance. Restaurant Industry Sales. http://www.restaurant.org/NewsResearch/Research/Facts-at-a-Glance (accessed November 2014).

7. Block JP, Condon SK, Kleinman K et al. (2013) Consumers' estimation of calorie content at fast food restaurants: cross sectional observational study. BMJ 346, f2907-f2916.

8. Rosenheck R (2008) Fast food consumption and increased caloric intake: a systematic review of a trajectory towards weight gain and obesity risk. Obes Rev 9, 535-547.

9. Bezerra IN, Curioni C \& Sichieri R (2012) Association between eating out of home and body weight. Nutr Rev 70, 65-79.

10. Lachat C, Nago E, Verstraeten R et al. (2012) Eating out of home and its association with dietary intake: a systematic review of the evidence. Obes Rev 13, 329-346.

11. Pereira MA, Kartashov AI, Ebbeling CB et al. (2005) Fast-food habits, weight gain, and insulin resistance (the CARDIA study): 15-year prospective analysis. Lancet 365, 36-42.

12. World Health Organization (2014) Overweight and obesity, Fact sheet no. 311. http://www.who.int/mediacentre/ factsheets/fs311/en/ (accessed November 2014).

13. Public Health England (2014) Obesity and Health. http:// www.noo.org.uk/NOO_about_obesity/obesity_and_health (accessed November 2014).

14. Danish National Board of Health (2003) National Action Plan Against Obesity. Recommendations and Perspectives, Short version. Copenhagen: Danish National Board of Health.

15. Hammond RA \& Levine R (2010) The economic impact of obesity in the United States. Diabetes Metab Syndr Obes $\mathbf{3}$, 285-295.

16. Liu PJ, Roberto CA, Liu LJ et al. (2012) A test of different menu labeling presentations. Appetite 59, 770-777.

17. Krieger J \& Saelens BE (2013) Impact of Menu Labeling on Consumer Behavior: A 2008-2012 Update. Princeton, NJ: Robert Wood Johnson Foundation.
18. New South Wales Food Authority (2013) Evaluation of Kilojoule Menu Labelling. Newington. NSW: NSW Food Authority.

19. Food Safety Authority of Ireland (2012) Calories on Menus in Ireland. Report on a National Consultation June 2102. Dublin: FSAI.

20. Roberto CA, Agnew H \& Brownell KD (2009) An observational study of consumers' accessing of nutrition information in chain restaurants. Am J Public Health 99, 820-821.

21. Vanderlee L \& Hammond D (2014) Does nutrition information on menus impact food choice? Comparisons across two hospital cafeterias. Public Health Nutr 17, 1393-1402.

22. Auchincloss AH, Mallya GG, Leonberg BL et al. (2013) Customer responses to mandatory menu labeling at full-service restaurants. Am J Prev Med 45, 710-719.

23. Campos S, Doxey J \& Hammond D (2011) Nutrition labels on pre-packaged foods: a systematic review. Public Health Nutr 14, 1496-1506.

24. Storcksdieck GBS \& Wills JM (2012) Nutrition labeling to prevent obesity: reviewing the evidence from Europe. Curr Obes Rep 1, 134-140.

25. Sassi F, Cecchini M, Lauer J et al. (2009) Improving Lifestyles, Tackling Obesity: The Health and Economic Impact of Prevention Strategies. Paris: OECD.

26. The Nielsen Company (2012) Battle of the Bulge \& Nutrition Labels. Healthy Eating Trends Around the World. New York: The Nielsen Company.

27. Department of Health, England (2011) The Public Health Responsibility Deal, March 2011. London: Department of Health, England.

28. Food Standards Agency, Northern Ireland (n.d.) Caloriewise scheme. http://www.food.gov.uk/northern-ireland/nutritionni/ caloriewise (accessed October 2014).

29. US Food and Drug Administration (2015) Menu and Vending Machines Labeling Requirements. http://www.fda. gov/Food/IngredientsPackagingLabeling/LabelingNutrition/ ucm217762.htm (accessed October 2015).

30. New South Wales Food Authority (2014) kJ labelling: fast \& snack food menu initiative. http://www.foodauthority.nsw. gov.au/industry/legislation/proposals-policy/fast-choices. VHWIouG_Tp (accessed November 2014).

31. Government of South Australia (n.d.) User Guide. Display of Kilojoules at Multiple-Site Food Businesses. Adelaide, SA: Government of South Australia.

32. Australian Capital Territory Legislative Assembly (2011) Food (Nutritional Information) Amendment Bill 2011. Explanatory Statement. Canberra, ACT: ACT Legislative Assembly.

33. Legislative Assembly of Ontario (2015) Bill 45, Making Healthier Choices Act, 2015. Toronto, ON: Legislative Assembly of Ontario.

34. European Food Information Council (2015) EUFIC's Global Update on Nutrition Labelling. Brussels: EUFIC.

35. US Food and Drug Administration (2014) Food Labeling; Nutrition Labeling of Standard Menu Items in Restaurants and Similar Retail Food Establishments. https://www. federalregister.gov/articles/2014/12/01/2014-27833/foodlabeling-nutrition-labeling-of-standard-menu-items-inrestaurants-and-similar-retail-food (accessed December 2014).

36. Sinclair SE, Cooper M \& Mansfield ED (2014) The influence of menu labeling on calories selected or consumed: a systematic review and meta-analysis. J Acad Nutr Diet 114, $1375-1388$.

37. Swartz JJ, Braxton D \& Viera AJ (2011) Calorie menu labeling on quick-service restaurant menus: an updated systematic review of the literature. Int J Behav Nutr Phys Act 8, 135-142.

38. Holmes AS, Serrano EL, Machin JE et al. (2013) Effect of different children's menu labeling designs on family purchases. Appetite 62, 198-202. 
39. Ellison B, Lusk JL \& Davis D (2013) Looking at the label and beyond: the effects of calorie labels, health consciousness, and demographics on caloric intake in restaurants. Int $J$ Behav Nutr Phys Act 10, 21-29.

40. Roseman MG, Mathe-Soulek K \& Higgins JA (2013) Relationships among grocery nutrition label users and consumers' attitudes and behavior toward restaurant menu labeling. Appetite 71, 274-278.

41. R Core Team (2014) R: A Language and Environment for Statistical Computing, 3.03 ed. Vienna: R Foundation for Statistical Computing.

42. Higgins JPT, Thompson SG, Deeks JJ et al. (2003) Measuring inconsistency in meta-analyses. BMJ 327, 557-560.

43. James A, Adams-Huet B \& Shah M (2014) Menu labels displaying the kilocalorie content or the exercise equivalent: effects on energy ordered and consumed in young adults. Am J Health Promot 29, 294-302.

44. Hammond D, Goodman S, Hanning R et al. (2013) A randomized trial of calorie labeling on menus. Prev Med 57, 860-866.

45. Krieger JW, Chan NL, Saelens BE et al. (2013) Menu labeling regulations and calories purchased at chain restaurants. Am J Prev Med 44, 595-604.

46. Elbel B, Mijanovich T, Dixon LB et al. (2013) Calorie labeling, fast food purchasing and restaurant visits. Obesity (Silver Spring) 21, 2172-2179.

47. Brissette I, Lowenfels A, Noble C et al. (2013) Predictors of total calories purchased at fast-food restaurants: restaurant characteristics, calorie awareness, and use of calorie information. J Nutr Educ Behav 45, 404-411.

48. Dodds P, Wolfenden L, Chapman K et al. (2014) The effect of energy and traffic light labelling on parent and child fast food selection: a randomised controlled trial. Appetite $\mathbf{7 3}$, 23-30.

49. Morley B, Scully M, Martin J et al. (2013) What types of nutrition menu labelling lead consumers to select less energydense fast food? An experimental study. Appetite 67, 8-15.

50. Dowray S, Swartz JJ, Braxton D et al. (2013) Potential effect of physical activity based menu labels on the calorie content of selected fast food meals. Appetite 62, 173-181.

51. Harnack LJ \& French SA (2008) Effect of point-of-purchase calorie labeling on restaurant and cafeteria food choices: a review of the literature. Int J Behav Nutr Phys Act 5, 51.

52. Kiszko KM, Martinez OD, Abrams C et al. (2014) The influence of calorie labeling on food orders and consumption: a review of the literature. I Community Health 39, 1248-1269.

53. Long MW, Tobias DK, Cradock AL et al. (2015) Systematic review and meta-analysis of the impact of restaurant menu calorie labeling. Am J Public Health 105, e11-e24.

54. Dumanovsky T, Huang CY, Bassett MT et al. (2010) Consumer awareness of fast-food calorie information in New York City after implementation of a menu labeling regulation. Am J Public Health 100, 2520-2525.

55. Berman M \& Lavizzo-Mourey R (2008) Obesity prevention in the information age. Caloric information at the point of purchase. JAMA 300, 433-435.

56. Ludwig DS \& Brownell KD (2009) Public health action amid scientific uncertainty. The case of restaurant calorie labeling regulations. JAMA 302, 434-435.

57. Larson N \& Story M (2009) Menu Labeling: Does Providing Nutrition Information at the Point of Purchase Affect Consumer Behavior? Princeton. NJ: Robert Wood Johnson Foundation.

58. Roberto CA, Schwartz MB \& Brownell KD (2009) Rationale and evidence for menu-labeling legislation. Am J Prev Med 37, 546-551.

59. Nestle M (2013) Menu labelling: What's new? http://www. foodpolitics.com/2013/04/menu-labeling-whats-new/ (accessed July 2014).
60. Hartocollis A (2009) Calorie postings don't change habits, study finds. New York Times, 6 October; available at http://www. nytimes.com/2009/10/06/nyregion/06calories.html?_r=0

61. Public Health Law Center, William Mitchell College of Law (2010) Menu Labelling. http://publichealthlawcenter.org/ topics/healthy-eating/menu-labeling (accessed November 2014).

62. Farley TA, Caffarelli A, Bassett MT et al. (2009) New York City's fight over calorie labeling. Health Aff (Millwood) 28, w1098-w1109.

63. Center for Science in the Public Interest (2011) State and Local Menu Labeling Policies. http://cspinet.org/new/pdf/ ml_map.pdf (accessed June 2014).

64. Cohn EG, Larson EL, Araujo C et al. (2012) Calorie postings in chain restaurants in a low-income urban neighborhood: measuring practical utility and policy compliance. J Urban Health 89, 587-597.

65. Nikolaou CK, Hankey CR \& Lean MEJ (2014) Preventing weight gain with calorie-labeling. Obesity (Sliver Spring) 22, 2277-2283.

66. Bruemmer B, Krieger J, Saelens BE et al. (2012) Energy, saturated fat, and sodium were lower in entrees at chain restaurants at 18 months compared with 6 months following the implementation of mandatory menu labeling regulation in King County, Washington. J Acad Nutr Diet 112, 1169-1176.

67. Namba A, Auchincloss A, Leonberg BL et al. (2013) Exploratory analysis of fast-food chain restaurant menus before and after implementation of local calorie-labeling policies, 2005-2011. Prev Chronic Dis 10, e101-e108.

68. Bauer KW, Hearst MO, Earnest AA et al. (2012) Energy content of US fast-food restaurant offerings: 14-year trends. Am J Prev Med 43, 490-497.

69. Booth SL, Sallis JF, Ritenbaugh C et al. (2001) Environmental and societal factors affect food choice and physical activity: rationale, influences, and leverage points. Nutr Rev 59, 3 Pt 2, S21-S39.

70. Eertmans A, Baeyens F \& Van den Bergh O (2001) Food likes and their relative importance in human eating behavior: review and preliminary suggestions for health promotion. Health Educ Res 16, 443-456.

71. Rydell SA, Harnack LJ, Oakes JM et al. (2008) Why eat at fast-food restaurants: reported reasons among frequent consumers. J Am Diet Assoc 108, 2066-2070.

72. Schindler J, Kiszko K, Abrams C et al. (2013) Environmental and individual factors affecting menu labeling utilization: a qualitative research study. J Acad Nutr Diet 113, 667-672.

73. Swartz JJ, Dowray S, Braxton D et al. (2013) Simplifying healthful choices: a qualitative study of a physical activity based nutrition label format. Nutr J 12, 72-81.

74. Ray K, Clegg S, Davidson R et al. (2013) Evaluation of Caloriewise: a Northern Ireland Pilot of the Display of Calorie Information in Food Catering Businesses. London: Policy Studies Institute, University of Westminster.

75. Powell LM \& Nguyen BT (2013) Fast-food and full-service restaurant consumption among children and adolescents: effect on energy, beverage, and nutrient intake. JAMA Pediatr 167, 14-20.

76. Auchincloss AH, Leonberg BL, Glanz K et al. (2014) Nutritional value of meals at full-service restaurant chains. J Nutr Educ Behav 46, 75-81.

77. Urban LE, Lichtenstein AH, Gary CE et al. (2013) The energy content of restaurant foods without stated calorie information. JAMA Intern Med 173, 1292-1299.

78. Scourboutakos MJ \& L'Abbe MR (2012) Restaurant menus: calories, caloric density, and serving size. Am J Prev Med $\mathbf{4 3}$, 249-255.

79. Schwartz J, Riis J, Elbel B et al. (2012) Inviting consumers to downsize fast-food portions significantly reduces calorie consumption. Health Aff (Millwood) 31, 399-407. 
80. Elbel B, Kersh R, Brescoll VL et al. (2009) Calorie labeling and food choices: a first look at the effects on low-income people in New York City. Health Aff (Millwood) 28, w1110-w1121.

81. Bassett MT, Dumanovsky T, Huang C et al. (2008) Purchasing behavior and calorie information at fast-food chains in New York City, 2007. Am J Public Health 98, 1457-1459.

82. Food and Drug Administration (2011) Food labeling: nutrition labeling of standard menu items in restaurants and similar retail food establishments notice of proposed rulemaking. http://www.fda.gov/downloads/Food/LabelingNutrition/ UCM249276.pdf (accessed November 2014).

83. Harnack LJ, French SA, Oakes JM et al. (2008) Effects of calorie labeling and value size pricing on fast food meal choices: results from an experimental trial. Int J Behav Nutr Phys Act 5, 63.

84. Bollinger B, Leslie P \& Sorensen A (2010) Calorie Posting in Chain Restaurants. Cambridge, MA: National Bureau of Economic Research.

85. Feldman C, Harwell H \& Brusca J (2013) Using student opinion and design inputs to develop an informed university foodservice menu. Appetite 69, 80-88.

86. Sonnenberg L, Gelsomin E, Levy DE et al. (2013) A traffic light food labeling intervention increases consumer awareness of health and healthy choices sat the pointof-purchase. Prev Med 57, 253-257.

87. Thorndike AN, Sonnenberg L, Riis J et al. (2012) A 2-phase labeling and choice architecture intervention to improve healthy food and beverage choices. Am J Public Health 102, $527-533$.

88. Grunert K \& Wills J (2007) A review of European research on consumer response to nutrition information on food labels. J Public Health 15, 385-399.

89. Fitch RC, Harnack LJ, Neumark-Sztainer DR et al. (2009) Providing calorie information on fast-food restaurant menu boards: consumer views. Am J Health Promot 24, $129-132$.

90. Blumenthal K \& Volpp KG (2010) Enhancing the effectiveness of food labeling in restaurants. JAMA 303, 553-554.

91. Sarink D, Peeters A, Freak-Poli R et al. (2014) The impact of mandatory menu energy labelling on socio-economic disparities in overweight and obesity. Obes Res Clin Pract 7, Suppl. 2, e123.

92. Yoon HJ \& George $\mathrm{T}$ (2012) Nutritional information disclosure on the menu: Focusing on the roles of menu context, nutritional knowledge and motivation. Int $J$ Hospital Manage 31, 1187-1194. 